01.1;08.3;09.4

\title{
Оптоакустический генератор ультразвука на основе структуры с таммовским плазмоном и органическим активным слоем
}

\author{
(C) Е.И. Гиршова ${ }^{1,2}$, Е.П. Микитчук ${ }^{3}$, А.В. Белоновский ${ }^{1,2}$, К.М. Морозов ${ }^{1,2}$, К.А. Иванов ${ }^{2}$ \\ ${ }^{1}$ Санкт-Петербургский национальный исследовательский Академический университет им. Ж.И. Алфёрова РАН, \\ Санкт-Петербург, Россия \\ ${ }^{2}$ Университет ИТМО, Санкт-Петербург, Россия \\ ${ }^{3}$ Белорусский государственный университет, Минск, Беларусь \\ E-mail: ilinishna@gmail.com
}

Поступило в Редакцию 26 ноября 2020г.

В окончательной редакции 20 декабря 2020 г.

Принято к публикации 20 декабря 2020г.

Рассматривается усовершенствование оптоакустического генератора на основе структуры с таммовским плазмоном в качестве активной среды за счет добавления слоя органического материала (полидиметилсилоксана), имеющего чрезвычайно высокий коэффициент температурного расширения. Проведено моделирование свойств структуры, показавшее, что использование полидиметилсилоксана в качестве дополнительного слоя структуры оптоакустического преобразователя является целесообразным на частотах до $50 \mathrm{MHz}$. Показано также, что добавление органического слоя приводит к увеличению эффективности оптоакустического преобразования на четыре порядка.

Ключевые слова: ультразвуковой генератор, таммовский плазмон, полидиметилсилоксан.

DOI: 10.21883/PJTF.2021.07.50793.18635

В основе принципа работы оптоакустического генератора (ОАГ) лежит поглощение модулированного лазерного излучения активной средой, что приводит к ее нагреву и расширению, вызывающему излучение ультразвуковой волны. В перерыве между лазерными импульсами структура остывает, и повторяющиеся колебания температуры за счет эффекта температурного расширения порождают механические колебания структуры [1-3].

В качестве активной среды преобразователя могут быть использованы металлические пленки [4], металлические наночастицы [5], углеродные нанотрубки [6], органические полимеры [7] и другие соединения. Для увеличения эффективности работы генератора необходимо увеличить коэффициент поглощения света структурой [8]. Недавно было показано, что применение структур с таммовскими плазмонами (рис. 1) позволяет добиться полного поглощения лазерного излучения с произвольной длиной волны и тем самым увеличить эффективность преобразования света в ультразвук [9]. Настоящая работа направлена на оценку целесообразности применения дополнительного слоя полидиметилсилоксана в структуре оптоакустического преобразователя для увеличения его энергоэффективности.

Интенсивность ультразвука с частотой $f$ можно выразить через амплитуду механических колебаний поверхности $B$

$$
J=\frac{\rho_{m} v}{2}(2 \pi f B)^{2},
$$

где $\rho_{m}-$ плотность среды, в которой распространяется ультразвук, $v$ - скорость звука в этой среде. Изменение толщины пленки с коэффициентом теплового расши- рения $\varepsilon$ вследствие ее нагрева лазерным импульсом с плотностью энергии $G$ определяется выражением

$$
B=\varepsilon G /(c \rho),
$$

где $c$ - ее удельная теплоемкость, а $\rho-$ плотность.

Ключевой характеристикой любого преобразователя энергии является эффективность преобразования $\eta$, для которой, используя выражения (1) и (2), можно получить выражение

$$
\eta=\frac{J}{G f}=2 \pi^{2} \rho_{m} v G f\left(\frac{\varepsilon}{c \rho}\right)^{2} .
$$

Таким образом, эффективность преобразования определяется отношением коэффициента теплового расширения к объемной теплоемкости материала активной среды. В таблице приведены термодинамические характеристики некоторых металлов, диэлектриков и органических материалов, используемых для создания ОАГ.

Можно видеть, что органические соединения обладают более высоким коэффициентом теплового расширения, чем диэлектрики, причем рекордными характеристиками обладает полидиметилсилоксан, что обеспечивает высокие (порядка $10^{-3}$ ) значения $\eta$ оптоакустических генераторов на основе полидиметилсилоксана с металлическими наночастицами $[1,2]$.

На рис. 1 изображена исследуемая структура. Базовая структура с таммовским плазмоном состоит из распределенного брэгговского отражателя, составленного из девяти пар чередующихся слоев оксида кремния толщиной $169 \mathrm{~nm}$ и нитрида кремния толщиной $122 \mathrm{~nm}$, и металлического слоя толщиной $100 \mathrm{~nm}$. В предлагаемой 
Термодинамические характеристики некоторых материалов, используемых для создания ОАГ

\begin{tabular}{c|c|c|c|c|c|c|c|c}
\hline $\begin{array}{c}\text { Мате- } \\
\text { риал }\end{array}$ & $\begin{array}{c}c, \\
\mathrm{~J} /(\mathrm{kg} \cdot \mathrm{K})\end{array}$ & $\begin{array}{c}\kappa, \\
\mathrm{W} /(\mathrm{m} \cdot \mathrm{K})\end{array}$ & $\begin{array}{c}\rho, 10^{3} \\
\mathrm{~kg} / \mathrm{m}^{3}\end{array}$ & $\begin{array}{c}c \rho, 10^{6} \\
\mathrm{~J} /\left(\mathrm{K} \cdot \mathrm{m}^{3}\right)\end{array}$ & $\begin{array}{c}D, 10^{-6} \\
\mathrm{~m}^{2} / \mathrm{s}\end{array}$ & $\begin{array}{c}\varepsilon, 10^{-6} \\
\mathrm{~K}^{-1}\end{array}$ & $\begin{array}{c}\frac{\varepsilon}{c \rho}, 10^{-12} \\
\mathrm{~m}^{3} / \mathrm{J}\end{array}$ & $\begin{array}{c}T, \\
{ }^{\circ} \mathrm{C}\end{array}$ \\
\hline $\mathrm{Au}$ & 128 & 317 & 19.3 & 2.48 & 127 & 14.2 & 5.7 & 1064 \\
$\mathrm{Ag}$ & 235 & 235 & 10.4 & 2.45 & 96.15 & 19.5 & 7.9 \\
$\mathrm{Al}$ & 897 & 236 & 10.3 & 2.43 & 97 & 22 & 961 \\
$\mathrm{Mg}$ & 103 & 156 & 1.73 & 1.78 & 88 & 25 & 15 & 660 \\
$\mathrm{~Pb}$ & 130 & 35.3 & 11.3 & 1.45 & 30 & 28 & 19 & 327 \\
$\mathrm{SiO}_{2}$ & 772 & 1.38 & 2.2 & 1.698 & 0.812 & 0.5 & 0.29 & 1710 \\
$\mathrm{TiO}_{2}$ & 850 & 12.6 & 4.26 & 3.032 & 4.15 & 9.19 & 3.03 & 1843 \\
$\mathrm{Al}_{2} \mathrm{O}_{3}$ & 850 & 30 & 3.99 & 3.3915 & 8.84 & 8.1 & 2.38 & 2072 \\
$\mathrm{Si}_{3} \mathrm{~N}_{4}$ & 886 & 26.5 & 2.81 & 2.49 & 10.6 & 2.55 & 1.02 & 1900 \\
$\mathrm{InP}$ & 310 & 68 & 4.81 & 1.491 & 3.72 & 4.6 & 3.08 & 1060 \\
$\mathrm{PDMS}$ & 146 & 0.18 & 0.965 & 0.14 & 0.11 & 300 & 2142 & 210 \\
$\mathrm{PVDF}$ & 1200 & 0.2 & 1.78 & 2.1 & 17 & 130 & 61.9 & 150 \\
$\mathrm{HDPE}$ & 540 & 0.4 & 0.97 & 0.523 & 0.55 & 200 & 382 & 370
\end{tabular}

Пр и м е ча н и е. $c$ - удельная теплоемкость, $\kappa-$ теплопроводность, $\rho-$ плотность, $c \rho-$ объемная теплоемкость, $D-$ температуропроводность, $\varepsilon-$ коэффициент теплового расширения, $T$ - температура плавления материалов, которые могут быть использованы в конструкции оптоакустического генератора (для полимерных материалов PDMS (полидиметилсилоксан), PVDF (поливинилиденфторид), НDPE (полиэтилен высокой плотности) $T$ - температура химического разложения).

усовершенствованной схеме поверх золота наносится полидиметилсилоксан $(100 \mathrm{~nm})$, а на него - слой золота толщиной $500 \mathrm{~nm}$ для облегчения отведения тепла от органического слоя (дополнительные слои изображены на рис. 1 справа). Суммарная толщина базовой структуры составляет $2719 \mathrm{~nm}$, структуры с дополнительными слоями - $3319 \mathrm{~nm}$.

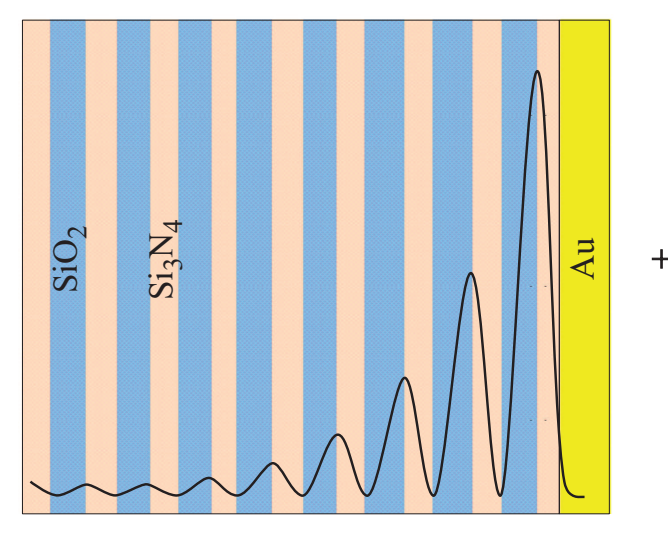

OAG on Tamm plasmon structure

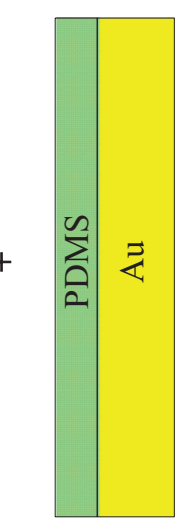

$\underbrace{}_{\text {Additional }}$ layers
Рис. 1. Схема фотоакустического преобразователя на основе структуры с таммовским плазмоном и дополнительным слоем полидиметилсилоксана (PDMS). Слева изображена базовая структура с таммовским плазмоном, состоящая из распределенного брэгговского отражателя (MDBR), составленного из чередующихся слоев оксида кремния толщиной $169 \mathrm{~nm}$ и нитрида кремния толщиной $122 \mathrm{~nm}$, и металлического слоя толщиной $100 \mathrm{~nm}$. Справа показаны дополнительные слои: слой полидиметилсилоксана $(100 \mathrm{~nm})$ и слой золота $(500 \mathrm{~nm})$. Сплошной линией представлено распределение квадрата электрического поля в структуре при облучении лазером на длине волны $980 \mathrm{~nm}$.
Полидиметилсилоксан обладает высоким коэффициентом температурного расширения [10], что делает его перспективным материалом для фотоакустического преобразователя. Однако он, как и большинство органических соединений, обладает низкой теплопроводностью [11], что увеличивает время температурной релаксации системы и уменьшает верхний предел допустимых частот. В связи с этим особенно важно обеспечить хорошее отведение тепла от органического слоя, поэтому в качестве металлической части плазмонной структуры был выбран слой золота. В качестве материалов распределенного брэгговского отражателя были выбраны $\mathrm{SiO}_{2}$ и $\mathrm{Si}_{3} \mathrm{~N}_{4}$, так как нитрид кремния также обладает хорошей теплопроводностью и эти два материала имеют довольно высокий оптический контраст на заданной частоте [12].

Параметры структуры были выбраны таким образом, чтобы обеспечить полное поглощение света на частоте таммовского плазмона, равной $1.26 \mathrm{eV}$, что дает возможность использовать для ОАГ дешевые и мощные полупроводниковые лазеры на основе GaAs для генерации ультразвука.

Зная распределение поля, можно определить пространственную и временну́ю плотность тепловыделения в структуре и распределения температуры $\Delta T(x)$ в ней путем решения неоднородного уравнения теплопроводности [9] и на основании этого оценить смещение поверхности образца

$$
\Delta x=\int \varepsilon \Delta T(x) d x
$$

Зная амплитуду механических колебаний, можно с помощью уравнений (1) и (3) рассчитать коэффициент эффективности оптоакустического преобразования. Необходимо отметить, что в том случае, когда система не 


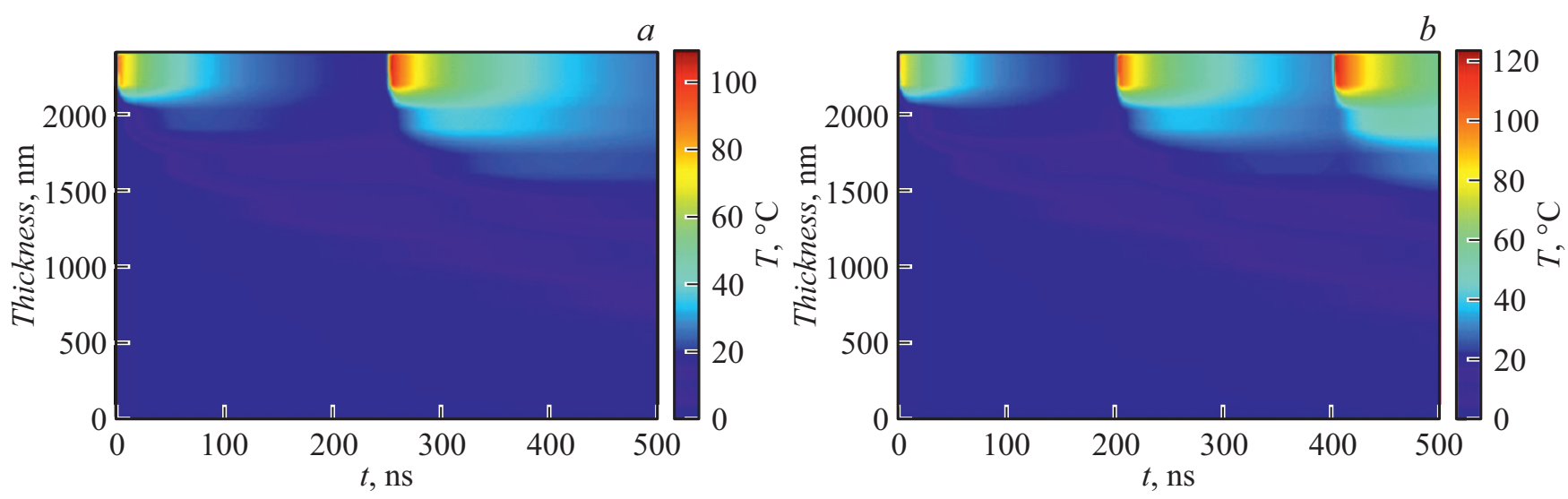

Рис. 2. Пространственное и временно́е распределение температуры в структуре. Облучение синусоидальными импульсами продолжительностью $5 \mathrm{~ns}$ с энергией $100 \mathrm{~mJ} / \mathrm{cm}^{2}$ и частотой $4(a)$ и $5 \mathrm{MHz}(b)$.

успевает полностью релаксировать между соседними лазерными импульсами, происходит постепенный ее нагрев до тех пор, пока не будет достигнут стационарный режим. Для определения эффективности энергопреобразования более корректно брать именно амплитуду механических колебаний в установившемся стационарном режиме при облучении модулированным лазерным излучением, а не одиночным импульсом. Как правило, эффективность оптоакустического преобразования измеряют при облучении одиночным импульсом [1-3], но более адекватным было бы определение эффективности при облучении монохроматической волной, что и было реализовано для оптоакустического генератора на базе структуры с таммовским плазмоном и дополнительным слоем полидиметилсилоксана. На рис. 2 приведено пространственное и временно́е распределение температуры в структуре при облучении с различными частотами модуляции. Видно, что на высоких частотах температурная релаксация не происходит, за счет чего снижается амплитуда механических колебаний. Этот эффект невозможно оценить при исследовании энергопреобразования одиночного импульса.

Поскольку эффективность оптоакустического преобразования пропорциональна частоте модуляции лазера и соответственно частоте генерируемого ультразвука, она возрастает с частотой до тех пор, пока интервал между соседними импульсами достаточен для качественной температурной релаксации. Таким образом, пиковые значения эффективности преобразования достигаются в высокочастотной части спектра прибора, как правило на частотах порядка 50-100 MHz. Тем не менее в медицине и дефектоскопии, двух основных областях практического применения ультразвуковых генераторов, используемый диапазон составляет от 2 до $29 \mathrm{MHz}$, так как чем выше частота, тем меньше глубина проникновения волн в исследуемый объект. В свете этого для изучения объемных объектов большое значение имеют частоты порядка единиц мегагерц, эффективность фотоакустиче- ского преобразования на которых на два порядка ниже, чем для частот порядка сотен мегагерц.

На рис. 3, с приведена зависимость эффективности энергопреобразования в структуре с добавлением слоя полидиметилсилоксана толщиной $100 \mathrm{~nm}$ от частоты при облучении синусоидальными импульсами продолжительностью $5 \mathrm{~ns}$ с энергией $0.5 \mathrm{~mJ} / \mathrm{cm}^{2}$. Можно видеть, что эффективность энергопреобразования для структуры с полидиметилсилоксаном сначала возрастает с частотой, а затем начинает падать в связи с невозможностью нормально релаксировать. На рис. 3, $a$ изображены зависимости эффективностей энергопреобразования в структуpe с добавлением слоя полидиметилсилоксана толщиной $100 \mathrm{~nm}$ (штриховая линия) и без него (сплошная линия). Зависимости от частоты были рассчитаны при облучении синусоидальными импульсами продолжительностью $5 \mathrm{~ns}$ с энергией $0.5 \mathrm{~mJ} / \mathrm{cm}^{2}$. На рис. $3, b$ представлена зависимость отношения эффективности фотоакустического преобразования в структуре с добавлением слоя полидиметилсилоксана толщиной $100 \mathrm{~nm}$ к эффективности энергопреобразования обычной структуры из золота и распределенного брэгговского преобразователя. Видно, что с увеличением частоты выигрыш в энергоэффективности падает за счет того, что структура не успевает остывать из-за теплоизоляционных свойств полидиметилсилоксана. На частотах выше $50 \mathrm{MHz}$ при данной энергии импульса структура разогревается выше $150^{\circ} \mathrm{C}$, что недопустимо для полидиметилсилоксана [11]. Видно также, что внедрение в структуру оптоакустического генератора с таммовским плазмоном слоя полидиметилсилоксана на частотах порядка единиц и десятков мегагерц приводит к увеличению эффективности оптоакустического преобразования на четыре порядка.

Таким образом, можно заключить, что использование полидиметилсилоксана в качестве дополнительного слоя структуры оптоакустического преобразователя является целесообразным с точки зрения повышения эффективности энергопреобразования на частотах до $50 \mathrm{MHz}$. Повышение эффективности именно в этом диапазоне 

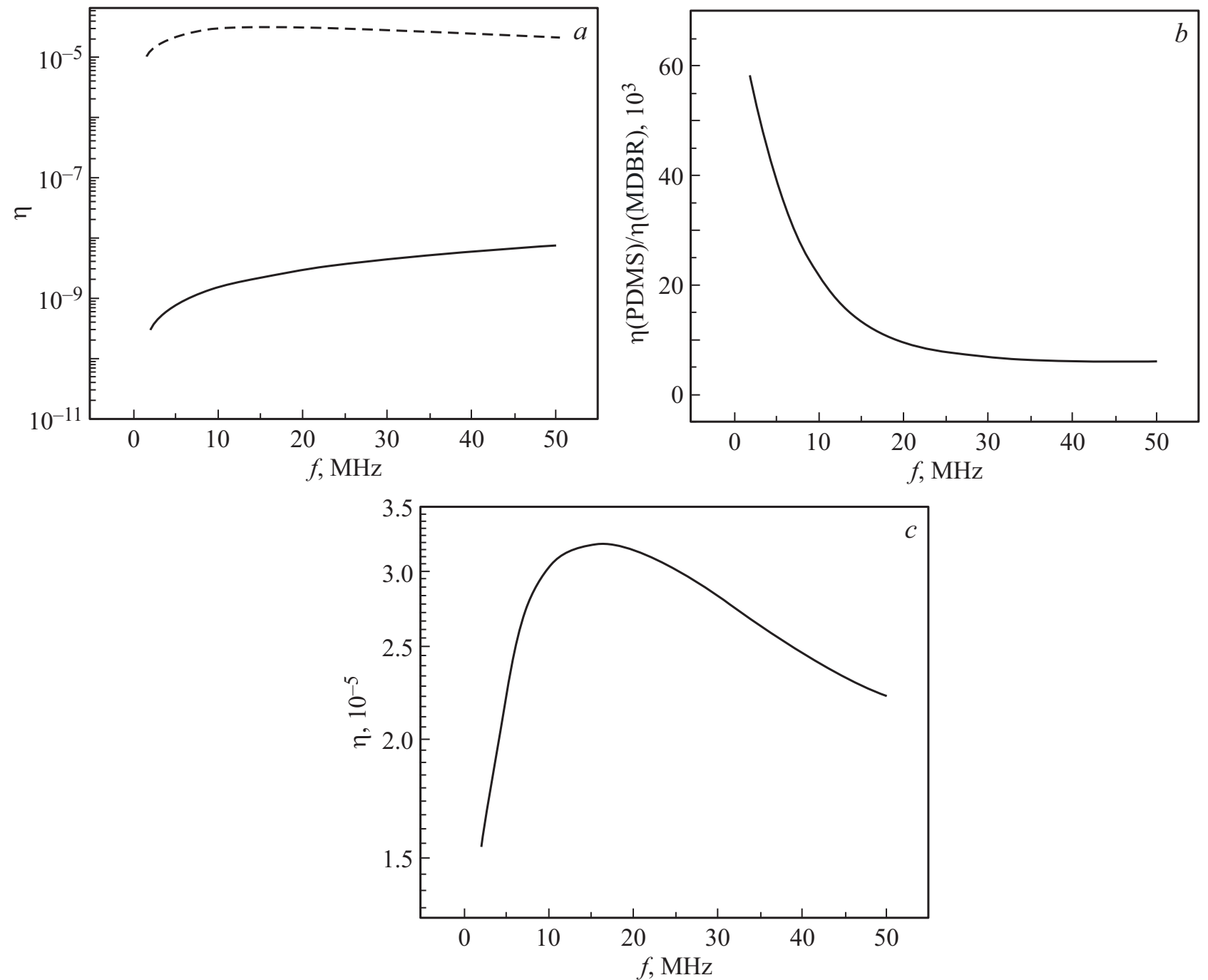

Рис. 3. $a$ - эффективность энергопреобразования в структуре с добавлением слоя полидиметилсилоксана толщиной $100 \mathrm{~nm}$ (штриховая линия) и без него (сплошная линия). $b$ - отношение эффективностей преобразования в структуре с добавлением слоя полидиметилсилоксана толщиной $100 \mathrm{~nm}$ и без него. Зависимости от частоты (части $a$ и $b$ ) были рассчитаны при облучении синусоидальными импульсами продолжительностью $5 \mathrm{~ns}$ с энергией $0.5 \mathrm{~mJ} / \mathrm{cm}^{2}$. $c$ - эффективность энергопреобразования в структуре с добавлением слоя полидиметилсилоксана толщиной $100 \mathrm{~nm}$ от частоты при облучении синусоидальными импульсами продолжительностью $5 \mathrm{~ns}$ с энергией $0.5 \mathrm{~mJ} / \mathrm{cm}^{2}$.

имеет прикладное значение. Данное усовершенствование конструкции приводит к увеличению эффективности на четыре порядка.

\section{Финансирование работы}

Исследование выполнено при финансовой поддержке Министерства науки и высшего образования РФ в рамках исследовательского проекта № FSRM-2020-0008 и при финансовой поддержке РФФИ и БРФФИ в рамках научного проекта № 19-52-04005.

\section{Конфликт интересов}

Авторы заявляют, что у них нет конфликта интересов.

\section{Список литературы}

[1] N. Wu, Y. Tian, X. Zou, V. Silva, A. Chery, X. Wang, J. Opt. Soc. Am. B, 29 (8), 2016 (2012).

[2] X. Zou, N. Wu, Y. Tian, X. Wang, Opt. Express, 22 (15), 18119 (2014).

[3] Y. Hou, J.-S. Kim, S.-W. Huang, S. Ashkenazi, L.J. Guo, M. O'Donnell, IEEE Trans. Ultrason. Ferroelectr. Freq. Control., 55 (8), 1867 (2008).

[4] E. Biagi, F. Margheri, D. Menichelli, IEEE Trans. Ultrason. Ferroelect. Freq. Contr., 48 (6), 1669 (2001).

[5] A.P. Mikitchuk, K.V. Kozadaev, Quant. Electron., 48 (7), 630 (2018).

[6] T. Lee, H.W. Baac, Q. Li, L.J. Guo, Adv. Opt. Mater., 6(24), 1800491 (2018). 
[7] H.W. Baac, J.G. Ok, A. Maxwell, K.-T. Lee, Y.-C. Chen, A.J. Hart, Z. Xu, E. Yoon, L.J. Guo, Sci. Rep., 2 (1), 989 (2012).

[8] M.A. Kaliteevski, A.A. Lazarenko, N.D. Il'inskaya, Yu.M. Zadiranov, M.E. Sasin, D. Zaitsev, V.A. Mazlin, P.N. Brunkov, S.I. Pavlov, A.Yu. Egorov, Plasmonics, 10 (2), 281 (2015).

[9] E.I. Girshova, A.P. Mikitchuk, A.V. Belonovski, K.M. Morozov, K.A. Ivanov, G. Pozina, K.V. Kozadaev, A.Yu. Egorov, M.A. Kaliteevski, Opt. Express, 28 (8), 26161 (2020).

[10] J. Bang, W.S. Lee, B. Park, H. Joh, H.K. Woo, S. Jeon, J. Ahn, C. Jeong, T.I. Kim, S.J. Oh, Adv. Funct. Mater., 29 (32), 1903047 (2019). https://doi.org/10.1002/adfm.201903047

[11] C. Chou, M. Yang, J. Therm. Anal. Calorim., 40 (2), 657 (2007).

[12] F. Völklein, Thin Solid Films, 188 (1), 27 (1990). https://doi.org/10.1016/0040-6090(90)90190-O 